\title{
Reflective practice from a systems perspective: enhancing service redesign and delivering optimal patient care
}

\begin{abstract}
Welcome to the first edition of FHJ of 2019. Sadly, I must start this editorial with the news that Professor Tim Evans, the founding editor-in-chief of this journal and lead college officer responsible for the groundbreaking Future Hospital Commission, passed away at the end of last year. In addition to having a profound effect on multiple aspects of healthcare in his many national leadership roles, and providing deep and lasting mentorship and guidance to individual health professionals, he had a simple but important message for his editorial team when he set up this journal: 'Be open-minded, be challenging and be brave'. Tim absolutely understood the need for an academic journal that could be an ongoing outlet for debate around the non-clinical aspects of healthcare, and provide a forum for reflection on the systems aspects of the NHS that are so fundamental in delivering optimal and high-quality patient care. He knew it would be a long road to deliver his vision of a thriving and important journal in this field; one that, in time, he hoped would develop a reach that would allow a transformational effect, but I also know he was proud of the significant progress and milestones we have achieved in delivering his vision to date. He will be greatly missed, and it has been honour to continue in this journal following in his (sizeable) footsteps.

It is also the time for me to pass on the mantle as editor-in-chief after my 3 years at the helm. It has been a real privilege to lead this unique and inspirational journal that, to me, is every bit as important to the inquisitive 21st-century doctor as the clinical journals that inform our practice. I have been blessed with an expert team around me and I would especially like to thank Professor Paul Jenkins for his tireless support and contribution to this journal as he steps down from the board for a well-earned retirement, and Professor Tom Downes, who has provided me with so much sage advice and guidance over the past 6 years that I do not really have words enough to say thank you. To the rest of my board, a huge thank you; your breadth of knowledge, erudite and considered debating skills and overarching desire to improve healthcare in the widest sense have given this journal its impact and impetus. Finally, my warmest appreciation must be to the Royal College of Physicians (RCP) publishing team; thank you for the journey, you are a special unit, and I wish you well as we enter the next chapter.
\end{abstract}

I would also like to welcome Dr Kevin Fox, who I know from my specialist cardiology world, as our new interim editor-in-chief; from my interaction with him in the past few months, I know he will bring yet more drive, passion, enthusiasm and challenge to this community. Kevin will lead this journal, with Tom as his deputy, until the formal appointment of my successor and I know I am handing over the journal into safe hands, and to individuals who will take this publication onwards and upwards.

So, turning to the work that Tim Evans set us on the path to deliver. As promised last year, we return to the theme of systems analysis again for this edition. The last edition focused on how systems engineering principles allow us to look at, and comprehend, complex, multi-faceted systems - such as the $\mathrm{NHS}$ - from an organisational perspective. ${ }^{1}$ It was focused on the principles used and how they may transform the way we approach our problems at a macrosystem level. This edition focuses more on the front-line implementation of such initiatives to support direct clinical care. The articles in this edition of $\mathrm{FHJ}$ present evidence from systems approaches and demonstrate how these data may allow us to reflect on, and understand, previously unrecognised factors that in turn may allow us to overcome the myriad of problems we face when trying to improve patient care. In this edition the key themes that emerge are how these data may be used to design new models of outpatient care, ${ }^{1,2}$ the importance of clinically focused activity data in modelling and delivering service redesign ${ }^{3}$ and workforce planning; ${ }^{4}$ and how we must focus on preparing our workforce adequately, especially at the start of professional lives and in new professional roles, whether junior doctors or physician associates (PAs). ${ }^{5-7}$

Many of these issues in this edition are highly topical, with recent mainstream media outlets reporting on group consultations, the RCP's opinions on the outdated models of outpatient care ${ }^{8}$ and the ongoing effects of the Brexit turmoil on workforce planning in the NHS. The content of this edition also led me to personally reflect on my preparedness for ward rounds in week one of my medical career, and the role of the supportive staff around me who were so critical to my early professional development. The evidence presented in this journal suggests that we still have some way to go in the preparation of medical students for their

Members of the editorial board
Wing Commander Edward Nicol
Editor-in-chief
Professor Tom Downes
Deputy editor-in-chief
Editorial board
Dr Na'eem Ahmed
Debra Armstrong

Dr Mohsin Choudry Dr John Dean Dr Kevin Fox Professor Paul Jenkins Dr Robert Klaber Dr David Morgan-Jones Dr Victoria Simpkin Dr Joanna Szram
Dr Emma Vaux Dr Louella Vaughan Ms Sheena Visram Dr Katharine Warburton Dr Stephen Webb Miss Jenny Isherwood Dr Frank Joseph Dr Mark Temple 
role. ${ }^{5}$ Although I was fortunate in that I felt at least somewhat prepared as I embarked on my medical career - and did undertake lone ward rounds twice a week - I also had a supportive team and firm structure around me, that I do not recognise in today's fragmented NHS system.

I was also extremely fortunate that in my first hospital we had staff with extended roles not dissimilar to the PA (although not as comprehensive), and these staff provided both reassurance and a guiding hand, both in a practical sense (such as phlebotomy) but also in a social sense (explaining the cultural and organisational aspects of the wards and hospital to the uninitiated!). In time, maybe this will be an additional, non-clinical, but integral PA role in assisting the newly qualified physician. As a white UK graduate, whose only linguistic challenge on transition from medical student to junior doctor was a subtle, and probably inconsequential change, in local dialect from Nottinghamshire to Cambridgeshire, I find the insights from the paper by Jalal et $a l^{9}$ a sobering reminder of the level of complexity and bewildering social and linguistic nuance that is faced by overseas healthcare professionals. These must be successfully overcome by those who come from overseas to work in the NHS, in addition to proving their clinical competence, and the statistics on the lack of support and highlighted General Medical Council actions reminds us all to be aware of our own unconscious bias, cultural ignorance and responsibility to care and support our own colleagues, as much as the patients we care for.

I hope you enjoy this month's edition and the myriad of educational content it contains. I hope it would have met Tim's unequivocally high standards and clear instructions!

\section{References}

1 Jones T, Darzi A, Egger G et al. A systems approach to embedding group consultations in the NHS. Future Healthcare Journal 2019;6:8-16.

2 Aziz A, Reynolds R, Ansari A. A population-based model of care for people with inflammatory bowel disease - patient-reported outcomes. Future Healthcare Journal 2019;6:30-35.

3 Lawton T, McCooe M. A novel modelling technique to predict resource requirements in critical care - a case study. Future Healthcare Journal 2019;6:17-20.

4 Kanagaratnam S, Dholakia S, Wood J et al. The WRaPT Process: A novel and patient-centred approach to workforce planning by a clinically active workforce. Future Healthcare Journal 2019;6:21-24.

5 Pearce J, Govan S and Harlinska A et al. Newly graduated doctors' experiences of conducting medical ward rounds alone: A regional cross-sectional study. Future Healthcare Journal 2019;6:47-51.

6 Burnett K, Armer N, McGregor ] et al. The career aspirations and expectations of student physician associates in the UK. Future Healthcare Journal 2019;6:36-40.

7 Roberts S, Howarth S, Millott H, Stroud L. 'What can you do then?' Integrating new roles into healthcare teams: regional experience with physician associates. Future Healthcare Journal 2019;6:61-66.

8 Royal College of Physicians. Outpatients: the future - adding value through sustainability. London: RCP, 2018.

9 Jalal M, Bardhan KD, Sanders D, Illing J. Overseas doctors of the NHS: migration, transition, challenges and towards resolution. Future Healthcare Journal 2019;6:76-82.

Wing Commander Ed Nicol Editor-in-chief 